\title{
Disproportionate short stature after cranial irradiation and combination chemotherapy for leukaemia
}

\author{
H A Davies, E Didcock, M Didi, A Ogilvy-Stuart, J K H Wales, S M Shalet
}

\begin{abstract}
The effect of combination chemotherapy and cranial irradiation on final height and body proportions was retrospectively examined in a cohort of 142 children treated for acute lymphoblastic leukaemia (ALL). Eighty four children (48 girls, 36 boys) received $24 \mathrm{~Gy}$ cranial irradiation and 58 (35 girls, 23 boys) $18 \mathrm{~Gy}$. None had received testicular or spinal irradiation. A significant reduction in standing height SD score from diagnosis to final height was seen in all groups. Of the 109 children in whom sitting height measurements were available, $88(81 \%)$ had relatively shorter backs than legs and in $25(23 \%)$ this disproportion was of a marked degree. After mathematical correction for sitting height loss there was no longer a significant reduction in standing height SD score at final height in all except the 24 Gy group of girls. These data suggest that disproportion is a common finding after treatment for ALL and that, at least in some children, much if not all of the height loss seen is due to a reduction in sitting height. Possible explanations for this disproportion include a disturbance of puberty or an effect of chemotherapy on spinal growth, or both.

(Arch Dis Child 1994; 70: 472-475)
\end{abstract}

Acute lymphoblastic leukaemia (ALL) is the most common childhood malignancy, with an incidence of $3 \cdot 5 / 100000$. Over the last $15-20$ years there has been a marked improvement in survival rates so that about $70 \%$ of children with ALL can now expect to be cured. ${ }^{1}$ Traditionally, children with ALL have been treated with combination chemotherapy and cranial or craniospinal irradiation as central nervous system (CNS) prophylaxis. Before 1981 most children received a cranial irradiation dose of 21-25 Gy (usually 24 Gy). Since then, the standard prophylactic dose of cranial irradiation has been $18 \mathrm{~Gy}$.

Although cranial irradiation has been shown to be highly effective in reducing the risk of CNS relapse in these children, it has become increasingly clear that there may be long term sequelae of the radiotherapy, in particular effects on growth, pubertal development, and mild learning difficulties.

It is almost universally agreed that the higher doses of cranial radiotherapy (21-25 Gy) can cause significant standing height loss and reduced final height, ${ }^{2-5}$ but the effect of the lower dose of irradiation (18 Gy) has been less clear, at least partly because it is only recently that there have been sufficient numbers of these children at final height for assessment. Although disproportion with a relatively short back is known to occur after craniospinal irradiation, it has not been reported after cranial irradiation alone. ${ }^{6}$ In this study we examine the effect of lower and higher doses of prophylactic cranial irradiation on adult stature and body proportions after completion of growth.

\section{Patients and methods}

Children from three regional paediatric oncology/haematology centres (Sheffield, Manchester, and Nottingham) were retrospectively studied. Patients who had been treated for lymphoblastic leukaemia with combination chemotherapy and cranial irradiation as $\mathrm{CNS}$ prophylaxis and who had achieved final height were identified. All were in first remission and none had received gonadal or spinal irradiation. Children who had received any form of endocrine treatment were excluded from the study. Details of chemotherapy and radiotherapy were obtained from each child's notes. The children were divided into groups on the basis of sex and whether they had received low dose (18 Gy) or high dose (21-25 Gy) cranial irradiation as prophylaxis.

The chemotherapy they had received was assigned to one of three categories: standard, moderate, and intensive based on criteria used by Sklar et al. ${ }^{7}$ Standard regimens (for example, UKALL I, II, III, V, VII, and VIII) consisted of three drug induction treatment (for example, L-asparaginase, vincristine, and prednisolone) and a four drug maintenance treatment (for example, methotrexate, 6-mercaptopurine, prednisolone, and vincristine). Moderate regimens were similar to standard but with the addition of one or more drugs (for example, UKALL $\mathrm{X}$ ). Intensive regimens included higher doses of multidrug treatment (for example, UKALL IV and VI, Memphis V).

All auxological data available on each child were examined. Final height was the standing height achieved when the height velocity for the preceding year was less than $1 \mathrm{~cm} /$ year. Standing height SD score at diagnosis and final height, sitting height, and leg length SD scores at final height were calculated using the standards of Tanner and coworkers. ${ }^{8-10}$ The SD score is calculated by subtracting the population mean for a child of the same age from the observed measurement for a child 
and dividing by the SD for that population. Hence a tall child has a positive SD score and a small child a negative SD score. Using the SD score allows auxological data acquired in children of different ages to be compared. For a normally distributed population the mean SD score is zero and a score of between -2 and +2 includes $95 \cdot 44 \%$ of the population.

The change in height SD score for, each child was calculated by subtracting the SD score at final height from that at diagnosis.

For children in whom sitting heights at final height were available, a disproportion score was calculated using the formula sitting height SD score minus leg length SD score. A normally proportioned child would be expected to have a disproportion score of around zero as the SD score for both sitting height and leg length should be approximately equal whether the child is tall, small, or of average height. A disproportion score equal to or greater than \pm 2 represents significant disproportion. ${ }^{11}$ In view of concerns that secular trends may mean that the Tanner and Whitehouse sitting height/leg length standards are out of date, a second disproportion score was calculated for those children identified as having significant disproportion using more contemporary standards based on a cohort of normal Leeds children studied by Buckler. ${ }^{12}$

Finally, a 'corrected' final height SD score assuming normal body proportions was calculated for each child in whom a sitting height measurement was available to enable an assessment to be made of the contribution of sitting height loss to their overall height loss. This was done by multiplying the difference between sitting height and leg length SD score (that is, the disproportion score) by the SD in cm for sitting height. This gives a value equal to the extra sitting height in $\mathrm{cm}$ that the child would have had if they had not been disproportionate. The addition of this value to the final height gives a corrected final height allowing for spinal loss.

A paired $t$ test was used to compare standing height SD score at diagnosis with standing height SD score at final height and sitting height SD score with leg length SD score at final height. An unpaired $t$ test was used to compare change in height SD score between groups. Spearman's rank correlation was used to assess the effect of age at diagnosis and standing height SD score at diagnosis on final height and body proportions.

Table 1 Mean (SE mean) height SD score at diagnosis and at final height, mean ( $S E$ mean) change in height $S D$ score, and mean (SE mean) corrected change in height $S D$ score for girls and boys in both dose groups

\begin{tabular}{|c|c|c|c|c|}
\hline \multirow[b]{2}{*}{ Irradiation group } & \multicolumn{2}{|c|}{24 Gy irradiation } & \multicolumn{2}{|c|}{18 Gy irradiation } \\
\hline & $\begin{array}{l}\text { Girls } \\
(n=49)\end{array}$ & $\begin{array}{l}\text { Boys } \\
(n=35)\end{array}$ & $\begin{array}{l}\text { Girls } \\
(n=35)\end{array}$ & $\begin{array}{l}\text { Boys } \\
(n=23)\end{array}$ \\
\hline \multirow{2}{*}{$\begin{array}{l}\text { Height SD score at diagnosis } \\
\text { Height SD scores at final height } \\
\text { Change in height SD score } \\
\text { Corrected change in height SD } \\
\text { score }\end{array}$} & $\begin{array}{l}+0.08(0.18) \\
-1.52(0.18) \\
-1.55(0.16)\end{array}$ & $\begin{array}{l}+0.06(0.18) \\
-0.83(0.20) \\
-0.90(0.14)\end{array}$ & $\begin{array}{l}+0.23(0.18) \\
-0.81(0.15) \\
-1.04(0.20)\end{array}$ & $\begin{array}{l}+0.32(0.18) \\
-0.37(0.19) \\
-0.69(0.17)\end{array}$ \\
\hline & $-1.23(0.17)$ & $-0.41(0.22)$ & $-0.22(0.22)$ & $+0.04(0.20)$ \\
\hline
\end{tabular}

\section{Results}

PATIENTS

One hundred and forty two children were eligible for the study. Of these $84(59 \%)$ had received 21-25 Gy (48 girls, 36 boys) and 58 (41\%) 18 Gy ( 35 girls, 23 boys). Sitting heights at final height were available in 111 $(78 \%)$ children. The children were divided into four groups on the basis of their radiotherapy dose and their sex: $24 \mathrm{G}$ and $24 \mathrm{~B}$ being girls and boys respectively who received $21-25$ Gy and $18 \mathrm{G}$ and $18 \mathrm{~B}$ being girls and boys respectively who received 18 Gy cranial irradiation. Median age at diagnosis for $24 \mathrm{G}$ and 24B was 4.2 years (range $1.43-12.8$ ) and 4.9 years (range 1.6-13.7) respectively, and for $18 \mathrm{G}$ and $18 \mathrm{~B} 7 \cdot 3$ years (range $2 \cdot 4-13 \cdot 1$ ) and $9 \cdot 4$ years (range $1 \cdot 65-13 \cdot 9$ ).

\section{EFFECT ON FINAL HEIGHT}

Table 1 gives the mean standing height SD score for each group at diagnosis and at final height and the mean change in height SD score. In all groups there was a significant difference between height SD score at diagnosis and height SD score at final height (24G $\mathrm{p} \leqslant 0.00001 ; 24 \mathrm{~B} \mathrm{p}=0.0018 ; 18 \mathrm{G} \mathrm{p} \leqslant 0.00001$; $18 \mathrm{~B} \mathrm{p}=0.004)$. Thirty three $(69 \%)$ of the $24 \mathrm{G}$ group, $18(50 \%)$ of the $24 \mathrm{~B}$ group, $17(49 \%)$ of the $18 \mathrm{G}$ group, and seven $(30 \%)$ of the $18 \mathrm{~B}$ group lost more than one $\mathrm{SD}$ in height between diagnosis and final height. In terms of actual centimetres lost, $23(48 \%)$ of the $24 \mathrm{G}$ group, $11(31 \%)$ of the 24B group, $10(29 \%)$ of the $18 \mathrm{G}$ group, and four $(17 \%)$ of the $18 \mathrm{~B}$ group had a change in height SD score equivalent to a loss in height of $10 \mathrm{~cm}$ or more.

Although the change in height SD score was greater with $24 \mathrm{~Gy}$ than $18 \mathrm{~Gy}$ for both boys and girls, this difference only reached significance in the girls $(p=0.05)$ and was not significant in the boys $(p=0.47)$.

Change in height SD score loss was correlated with younger age at diagnosis and taller stature at diagnosis in the $24 \mathrm{G}, 18 \mathrm{G}$, and $18 \mathrm{~B}$ groups, but not the 24B group.

Using Spearman's rank correlation $r=0.53$, $\mathrm{p} \leqslant 0.002, r=0.55, \mathrm{p} \leqslant 0.002$, and $r=0.59$, $p \leqslant 0.01$ for age at diagnosis for $24 \mathrm{G}, 18 \mathrm{G}$, and $18 \mathrm{~B}$ respectively. For height $\mathrm{SD}$ score at diagnosis $r=-0.45, \mathrm{p} \leqslant 0.02, r=-0.67, \mathrm{p} \leqslant 0.002$, and $r=-0.45, p \leqslant 0.002$ for $24 \mathrm{G}, 18 \mathrm{G}$, and $18 \mathrm{~B}$ respectively.

EFFECT ON BODY PROPORTIONS

The figure gives the mean sitting height SD score and mean leg length SD score at final height for the four groups. In all groups there was a significant difference between sitting height SD score and leg length SD score at final height (24G $p=0.0001 ; 24 B \mathrm{p}=0.0023$; $18 \mathrm{G} p \leqslant 0.00001 ; 18 \mathrm{~B} \mathrm{p}=0.0003)$. Of the 111 (37 24G, $3024 \mathrm{~B}, 2618 \mathrm{G}, 1718 \mathrm{~B}$ ) children in whom sitting heights were available, $91(82 \%)$ had relatively shorter backs than legs. In 25 (23\%) (five $24 \mathrm{G}$, eight $24 \mathrm{~B}$, nine $18 \mathrm{G}$, three 18B) this disproportion was significant with more than two SD difference between sitting 


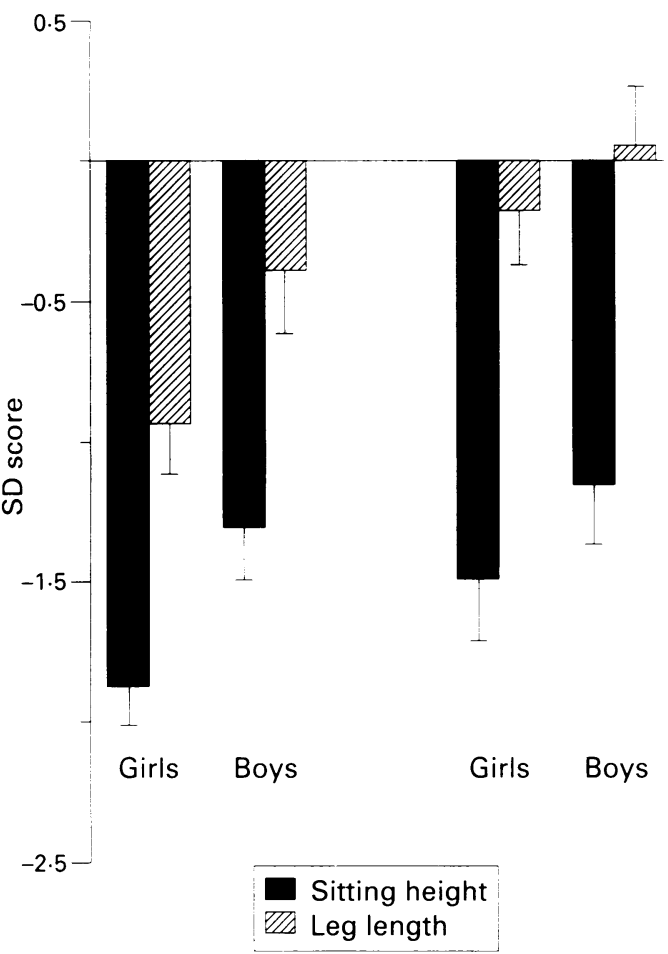

Mean sitting height and leg length SD score for boys and girls in the two dose groups. The error bars represent the SE mean for each group. A normally proportioned child should have a sitting height $S D$ score and leg length $S D$ score that are approximately equal.

height and leg length. Of the remaining 20, 17 had relatively shorter legs than backs, but only two of these patients had more than $1.5 \mathrm{SD}$ difference between sitting height and leg length and in none was the disproportion significant.

Table 2 gives the disproportion scores using the Tanner and coworkers ${ }^{8-10}$ and Buckler ${ }^{12}$ standards for the 25 patients with significant disproportion. In the $24 \mathrm{G}$ and $24 \mathrm{~B}$ groups respectively, two of 23 and six of 21 who had received 'standard' chemotherapy and three of 13 and two of eight who had 'intensive' chemotherapy had significant disproportion. In the $18 \mathrm{G}$ and $18 \mathrm{~B}$ groups respectively, five of 20 and three of 11 who had received standard chemotherapy, two of four and none of four who had 'moderate' chemotherapy, and one of two and none of one who had intensive chemotherapy had significant disproportion.

Table 1 gives the corrected change in height SD score for all groups. For all except the $24 \mathrm{G}$ group correction for sitting height loss meant that there was no longer a significant change in height SD score between diagnosis and final height. The change remained significant in the $24 \mathrm{G}$ group $(p=0 \cdot 0001)$.

\section{Discussion}

Lymphoblastic leukaemia is the most common childhood cancer and one of the most 'curable'. Hence there will be increasing numbers of children whose growth and development must be monitored and who will require counselling about likely late effects of their treatment as well as management of any adverse sequelae. Significant loss of standing height occurred in both the $24 \mathrm{G}$ and the $18 \mathrm{G}$ groups and although the loss was greater in the higher dose groups this difference was not significant. Indeed, with time it may be that the difference between the $18 \mathrm{G}$ and the $24 \mathrm{G}$ groups is shown to be even less than in this study as the median age at diagnosis for the $24 \mathrm{G}$ groups was significantly younger than the $18 \mathrm{~Gy}$ groups, allowing them more time for height loss. In addition, younger age at diagnosis is correlated with greater height loss anyway. This difference in median age at diagnosis arises because $18 \mathrm{~Gy}$ cranial irradiation as prophylaxis has only been widely used since 1981 so those at final height now are mainly those who were older at diagnosis. Other workers have found similar changes in standing height after cranial irradiation, though the numbers reported at final height after $18 \mathrm{~Gy}$ have been small. ${ }^{2} 457$

In this study we have shown that not only does cranial irradiation and combination chemotherapy cause significant loss of standing height, but it may also result in significant disproportion with a relatively short spine, which is a new observation. Eighty one per cent of those children in whom sitting heights were available had relatively shorter backs than legs and in nearly a quarter this disproportion was markedly significant. Of those who showed significant disproportion about 50\% had received $24 \mathrm{~Gy}$ and 50\% $18 \mathrm{~Gy}$ cranial irradiation. Interestingly, when a corrected final height is calculated with a compensatory allowance for the short spine, only in the $24 \mathrm{G}$ group is the change in standing height SD score from that at diagnosis still significant. This suggests that, at least in some children, much if not all of the height loss seen after treatment for ALL is due to loss of sitting height.

Table 2 Disproportion scores for the 25 children with significant disproportion using standards of Tanner et $\mathrm{al}^{8-10}$ and Buckler. ${ }^{12}$ Significant disproportion is defined as sitting height $S D$ score minus leg length $S D$ score greater than or equal to \pm 2 . For each group the number of children on whom sitting heights were available is given in parentheses

\begin{tabular}{|c|c|c|}
\hline $\begin{array}{l}\text { Study } \\
\text { group }\end{array}$ & $\begin{array}{l}\text { Tanner et al } \\
\text { disproportion score }\end{array}$ & $\begin{array}{l}\text { Buckler } \\
\text { disproportion score }\end{array}$ \\
\hline \multicolumn{3}{|l|}{$18 \mathrm{~Gy}$ irradiation } \\
\hline \multirow[t]{9}{*}{ Girls $(n=26)$} & $-2 \cdot 7$ & $-3 \cdot 0$ \\
\hline & $-2 \cdot 8$ & $-2 \cdot 6$ \\
\hline & $-3 \cdot 0$ & $-2 \cdot 7$ \\
\hline & $-2 \cdot 0$ & $-1 \cdot 6$ \\
\hline & $-2 \cdot 3$ & $-2 \cdot 3$ \\
\hline & $-2 \cdot 7$ & $-2 \cdot 7$ \\
\hline & $-4 \cdot 0$ & $-3 \cdot 9$ \\
\hline & $-2 \cdot 7$ & $-2 \cdot 6$ \\
\hline & $-2 \cdot 0$ & $-2 \cdot 0$ \\
\hline \multirow{3}{*}{ Boys $(n=17)$} & $-2 \cdot 3$ & $-2 \cdot 4$ \\
\hline & $-2 \cdot 0$ & $-1 \cdot 8$ \\
\hline & $-2 \cdot 0$ & $-2 \cdot 0$ \\
\hline \multirow{6}{*}{$\begin{array}{c}24 \text { Gy irradiation } \\
\text { Girls }(n=37)\end{array}$} & & \\
\hline & $-2 \cdot 3$ & $-2 \cdot 1$ \\
\hline & $-2 \cdot 3$ & $-2 \cdot 1$ \\
\hline & $-2 \cdot 1$ & $-2 \cdot 0$ \\
\hline & $-2 \cdot 2$ & $-2 \cdot 2$ \\
\hline & $-2 \cdot 1$ & $-2 \cdot 0$ \\
\hline \multirow[t]{8}{*}{ Boys $(n=30)$} & $-3 \cdot 4$ & $-3 \cdot 5$ \\
\hline & $-2 \cdot 4$ & $-2 \cdot 3$ \\
\hline & $-2 \cdot 3$ & $-2 \cdot 2$ \\
\hline & $-2 \cdot 3$ & $-2 \cdot 4$ \\
\hline & $-3 \cdot 2$ & $-2 \cdot 8$ \\
\hline & $-2 \cdot 0$ & -1.9 \\
\hline & $-2 \cdot 3$ & $-2 \cdot 5$ \\
\hline & $-2 \cdot 0$ & $-1 \cdot 8$ \\
\hline
\end{tabular}


Traditionally, loss of height potential in these children has been largely attributed to growth hormone insufficiency secondary to their cranial irradiation, with evidence suggesting that abnormalities of growth hormone secretion after $18 \mathrm{~Gy}$ are seen mainly during puberty. ${ }^{13}$ Radiation induced precocious puberty may also contribute to the eventual short stature. Neither growth hormone deficiency per se nor precocious puberty, however, are associated with marked skeletal disproportion. Furthermore, precocious puberty in the children treated for leukaemia occurs mainly in girls, whereas disproportion in our series was seen in both sexes. ${ }^{214}$ Thus an alternative explanation for the disproportion is required. In our study there were insufficient children with serial sitting height measurements to allow us to comment on the evolution of the disproportion and whether this took place predominantly in the prepubertal years or during puberty. None the less, much of the normal growth of the spine takes place during puberty and there has been one report that the duration of puberty is significantly attenuated in children treated for ALL. ${ }^{15}$ Thus the reduction in sitting height may reflect an alteration in the tempo of puberty.

Another possible explanation is that the disproportion is related to chemotherapy. The spine contains large numbers of epiphyses and if chemotherapy has a direct effect on the epiphysial growth plate it seems likely that this would result in greater loss in sitting height than leg length. There is a small amount of in vitro data and some clinical observations which support the idea that chemotherapy may act directly in this manner. ${ }^{1617}$ In our study group the numbers with significant disproportion were too small to draw any firm conclusions about the effect of chemotherapy schedules of varying intensities.

In the current United Kingdom ALL trial (UKALL XI) most children do not receive cranial irradiation as prophylaxis and it will therefore eventually be possible to determine the role of chemotherapy in abnormal growth and body proportions after treatment for ALL. As this trial did not start until October 1990, however, final height data from these children will not be available until the next century. In a large US study Sklar et $a l^{7}$ showed significant height loss in children who had received chemotherapy without any cranial irradiation, though this height loss was less than in those also receiving cranial irradiation. Sitting height data are not available in these children, but our data suggest that the loss seen at final height in their unirradiated group ( $-0.49 \mathrm{SD})$ could be explained by loss of sitting height alone.

Much uncertainty about growth after treatment for childhood leukaemia remains, but it seems likely that there are several factors that may contribute to the growth impairment seen. Growth hormone insufficiency and precocious puberty, which have been attributed to cranial irradiation, are well recognised adverse factors which in combination are likely to result in considerable loss of height potential. The finding of disproportion in our study is not readily explained by cranial irradiation unless it is postulated that a central control mechanism exists for proportionate growth or that cranial irradiation modifies the tempo of puberty. Cranial irradiation alone, however, does not appear to cause significant disproportion in children treated for brain tumours. ${ }^{6}$ It is more likely that a disturbance of pubertal growth in combination with a direct effect of chemotherapy on the cartilage growth plate are further key factors leading to growth impairment after treatment for leukaemia.

HAD and $M D$ are supported by the Leukaemia Research Fund. We thank Professor J S Lilleyman, Dr P M MorrisJones, Dr P Barbor, and Dr D A Walker for allowing us to use their patients.

1 Rivera GK, Pinkel D, Simone JV, Hancock ML, Crist WM Treatment of acute lymphoblastic leukaemia: 30 years' experience at St Jude's Children's Research Hospital NEngl f Med 1993; 329: 1289-95.

2 Uruena M, Stanhope R, Chessells JM, Leiper AD. Impaired pubertal growth in acute lymphoblastic leukaemia. Arch Dis Child 1991; 66: 1403-7.

3 Schriock EA, Schell MJ, Carter M, Hustu O, Ochs J Abnormal growth patterns and adult short stature in 115 long-term survivors of childhood leukaemia. $\mathcal{f}$ Clin Oncol 1991; 9: 400-5.

4 Clayton PE, Shalet SM, Morris-Jones PM, Price DA Growth in children treated for acute lymphoblastic leukaemia. Lancet 1988; i: 460-2.

5 Kirk J, Stevens MM, Monser MA, et al. Growth failure and growth hormone deficiency after treatment for acute rmphoblastic leukaemia. Lancet 1987; i: 190-3.

6 Shalet SM, Gibson B, Swindell R, Pearson D. Effect of spinal irradiation on growth. Arch Dis Child 1987; 62: 461-4.

7 Sklar C, Mertens A, Walter A, et al. Final height after treatment for childhood acute lymphoblastic leukaemia: comparison of no cranial irradiation with 1800 and 2400 cGy cranial irradiation. $\mathcal{F}$ Pediatr 1993; 123: 59-64.

8 Tanner JM, Whitehouse RH, Takaishi M. Standards for birth to maturity for height, weight, height velocity and weight velocity: British children, 1965. Part 1. Arch Dis Child 1966; 41: 454-7.

9 Tanner JM, Whitehouse RH, Takaishi M. Standards for birth to maturity for height, weight, height velocity and weight velocity: British children, 1965. Part 2. Arch Dis Child 1966; 41: 613-35.

10 Tanner JM, Whitehouse RH. Standards for sitting height and sub-ischial leg length from birth to maturity: British children. 1978. Ware: Castlemead Publications, 1979.

11 Wales JKH, Herber SM, Taitz LS. Height and body proportions in child abuse. Arch Dis Child 1992; 67: 632-5.

12 Buckler J. A longitudinal study of adolescent growth. London: Springer-Verlag, 1990: 109.

13 Moell C, Garwicz S, Westgren U, et al. Suppressed spontaneous secretion of growth hormone in girls after spontaneous secretion of growth hormone in girls after
treatment for acute lymphoblastic leukaemia. Arch Dis Child 1989; 64: 252-8.

14 Moell C, Garwicz S, Westgren U, Wiebe T. Disturbed pubertal growth in girls treated for acute lymphoblastic leukaemia. Pediatr Haematol Oncol 1987; 4: 1-5.

15 Quigley C, Cowell C, Jimenez M, et al. Normal or early development of puberty despite gonadal damage in children treated for acute lymphoblastic leukaemia. N Engl f Med 1989; 321: 143-51.

16 Shalet SM. The endocrine consequences of cytotoxic chemotherapy in childhood. Growth Matters 1990; 1: 2-6.

17 Cowell CT, Quigley CA, Moore B, et al. Growth and growth hormone therapy of children treated for leukaemia. Acta Paediatr Scand 1988; 343 (suppl); 152-61. 